\title{
Pesquisa em ensino de Química experimental: mapeamento das teses e dissertações apresentadas no Brasil de 2002 a 2011
}

Heloisa Helena de Jesus Ferreira

Carmem Lúcia Costa Amaral

\section{Resumo}

Este trabalho apresenta mapeamento e análise de resumos publicados no Banco de Teses e Dissertações da Coordenação de Aperfeiçoamento de Pessoal de Nível Superior (Capes) sobre pesquisas em ensino de Química experimental no período de 2002 a 2011. O objetivo foi conhecer como os pesquisadores estão desenvolvendo esse tipo de ensino no Brasil. O corpus foi categorizado por focos temáticos com o objetivo de facilitar a análise dos conteúdos, que utilizou o referencial teórico-metodológico segundo Bardin (2007). O primeiro foco trata as concepções, os saberes e o desenvolvimento profissional do professor. $O$ segundo foco trata o papel do aluno nos processos cognitivos e as estratégias de ensino. Como resultado, evidenciou-se um maior número de pesquisas sobre a aprendizagem dos estudantes, ancorados, principalmente, na perspectiva investigativa, que emprega estratégia de ensino que contribui para a construção de conceitos dos estudantes em relação ao conhecimento químico.

Palavras-chave: CAPES - Teses e Dissertações, ensino de Química experimental, aulas práticas de Química, atividades experimentais.

\section{Abstract}

This research present the mapping and analyses of abstracts regarding research work done on the teaching of Experimental Chemistry published in the Bank of Theses and Dissertations from Coordination for the Improvement of Higher Education Personnel (Capes) between 2002 and 2011. The goal was to investigate how researchers are developing this kind of education in Brasil. The Corpus has been divided into theme categories in order to facilitate the data analyses. The theoretical-methodological referential to this categorization was Bardin (2007). The first category deals with teachers' perceptions, knowledge and professional development. The second category deals with the student's role in the cognitive processes, as well as learning strategies. The results point to a higher number of research works that focus on the students' learning, mainly anchored to the investigative perspective which employs teaching strategy that contributes to the construction of students' concepts in relation to the knowledge of chemistry.

Keywords: CAPES - teaching of Experimental Chemistry, Chemistry practical classes, experiential activities. 


\section{Introdução}

As atividades experimentais para o ensino de Química constituem estratégias de ensino ainda pouco desenvolvidas, principalmente por falta de condições de uso de laboratório e pela insegurança de muitos professores que não tiveram acesso a laboratórios durante a sua formação (SUART et al., 2009). Isso pode ser constatado ainda nos dias de hoje, mesmo existindo um consenso entre muitos pesquisadores de que a experimentação é uma estratégia capaz de motivar e levar os alunos à aprendizagem, como explica Suart et al. (2010). Diante dessa constatação e reconhecendo a importância dessas atividades, concordamos com Santos e Schnetzler (1996) que a atividade experimental deve estar presente no currículo de Química por auxiliar o aluno na compreensão dos fenômenos químicos, buscando as respostas e explicações a partir de discussões, questionamentos e problematizações. Para esses autores, os alunos conseguem, dessa forma, construir os conhecimentos sobre os fenômenos e conceitos científicos, principalmente se eles têm oportunidades de propor questões para as atividades que envolvam resolução de problemas. Esse tipo de atividade é conhecido como atividade experimental investigativa.

Nesse sentido, buscando uma explicação do porquê os alunos conseguem construir os conhecimentos, desenvolvendo atividades experimentais, Gil-Perez et al. (1999) explica que a resolução de problemas exige dos estudantes uma atitude mais ativa e um esforço para buscar respostas próprias. E, por isso, essa estratégia contribui para o desenvolvimento das potencialidades criativas dos estudantes, despertando a curiosidade, a motivação e o interesse. Goi e Santos (2009,) pesquisando sobre atividades experimentais investigativas a partir da metodologia de resolução de problemas, constataram que essa estratégia permite o desenvolvimento da criatividade dos estudantes, bem como a aquisição de autonomia e segurança em relação aos aspectos conceituais dos problemas propostos e, ainda, desenvolve atitudes para construção de uma metodologia própria para resolver os problemas.

Trabalhando com atividades experimentais para o ensino de Química, concordamos com esses autores porque também constatamos na prática que uma participação mais ativa dos estudantes leva à aprendizagem, principalmente quando eles são estimulados a buscar respostas. Dessa forma, entendemos que, ao ensinar Química utilizando essas atividades, a escola cumpre o papel de formar cidadãos que sabem buscar as informações e transformá-las em conhecimento pessoal, para se posicionar e agir no meio em que vivem. Para isso, durante a experimentação devem ser realizadas discussões que levem ao desenvolvimento de habilidades de participação e julgamento, entre outras.

Apesar da importância dessas atividades no ensino de química, o que se observa é que em muitas escolas essas atividades não são desenvolvidas, principalmente pelo alto custo de instalação e manutenção de um laboratório, que requer equipamentos, reposição das vidrarias quebradas e o gasto com reagentes. Outros aspectos que devem ser levados em consideração são

DOI: Em andamento. 
a preocupação com a correta armazenagem de reagentes químicos e com o descarte apropriado dos resíduos gerados nesse laboratório, bem como a segurança de todos os usuários e a preservação do meio ambiente. Somam-se a esses aspectos, o fato de essas atividades necessitarem de um professor com preparo e segurança para desenvolver os experimentos, tendo inclusive tempo para testar cada um, antes de realizá-lo com os alunos, além do número de alunos nesse espaço.

Para viabilizar a realização dessas atividades, muitos professores procuram desenvolver experimentos com materiais alternativos de baixo custo, mas isso não descarta a necessidade de se preocupar com a segurança e com o tratamento de possíveis resíduos gerados. Essas considerações são endossadas e reforçadas por Gonçalves e Marques (2006), quando explicam que, além da falta de condições materiais para o desenvolvimento de experimentos, a falta de segurança é outra limitação, já que é essencial para a realização dessas atividades, pois não se pode colocar em risco a integridade física dos alunos. Esses autores consideram ainda que o professor precisa prevê o destino dos resíduos ou evitar sua geração, antes mesmo de realizar o experimento. Essa preocupação, segundo eles, contribui para que os alunos adquiram atitudes responsáveis não só relativas à geração e tratamento de resíduos, mas também às implicações sociais, econômicos e políticos advindos dessas atitudes.

O reconhecimento da importância da utilização das atividades experimentais como estratégia de ensino de Química levou pesquisadores dessa área a investigar sobre o que tem sido realizado nesse sentido. Algumas pesquisas mostraram que a forma e os meios com que a experimentação vem sendo desenvolvida diferem, principalmente, nas propostas investigadas. Por exemplo, Gonçalves e Marques (2006) investigaram as características dos discursos das atividades experimentais publicadas na seção Experimentos no ensino de Química da revista Química Nova na Escola, durante o período de 1995 a 2003. O objetivo da pesquisa desses autores foi problematizar a experimentação na formação de professores e repensar as características metodológicas das atividades experimentais, sinalizando possibilidades para o desenvolvimento de experimentos.

Outros trabalhos se preocuparam com o ensino de Química de um modo geral e sobre pesquisas em ensino de Química experimental. O exemplo mais representativo é o trabalho de Schnetzler (2002). Ela fez um estudo sobre as pesquisas em ensino de química nos 25 anos de existência da Sociedade Brasileira de Química (SBQ) (1977 a 2002), realizando uma série de levantamentos, como os artigos na revista Química Nova na Escola, os artigos publicados na seção de educação da revista Química Nova, as comunicações de pesquisa de membros da Divisão de Ensino de Química (DED) publicadas nos resumos das reuniões anuais da SBQ e os resumos de teses e dissertações brasileiras nessa área. Ela buscou ainda opiniões e informações de colegas, com no mínimo 10 anos de experiência na área, sobre a produção e tendência da área para apontar conquistas e perspectivas. 
De acordo com essa autora, no período investigado, foram produzidas 77 dissertações e 22 teses, sendo que $71 \%$ desses trabalhos investigaram o desenvolvimento e a avaliação de propostas de ensino, os problemas de ensino-aprendizagem, a análise de livros didáticos, os problemas de avaliação, a linguagem, as interações em sala de aula, a formação de professores e apenas $9 \%$ abordaram especificamente sobre o ensino experimental.

Queiroz et al. (2003) analisou os resumos apresentados na seção de Ensino de Química da Reunião Anual da Sociedade Brasileira de Química, no período de 1999 a 2003, com o objetivo de dar ao leitor uma visão geral sobre a produção acadêmica acerca do ensino de Química nos cinco anos pesquisados, considerando o número de trabalhos produzidos por área, região e nível de ensino. De acordo com esses autores houve um predomínio de pesquisas visando à elaboração de materiais didáticos (softwares, módulos instrucionais de ensino, experimentos com utilização de materiais de baixo custo), à análise de livros didáticos, a reflexões sobre as políticas educacionais, ao estudo das metodologias de ensino englobando o trabalho experimental e o trabalho de campo, à observação de programas de formação de professores e estudos sobre Tecnologias Educacionais, como a criação de softwares e sites educacionais e estudos relacionados à Educação Ambiental.

Depois de apresentar os objetivos das três pesquisas aqui considerada, passamos ao presente trabalho, que teve como objetivo investigar como os pesquisadores estão desenvolvendo esse tipo de ensino no Brasil. Para isso, realizamos uma análise nos resumos publicados no Banco de Teses e Dissertações da Capes, no período de 2002 a 2011. Nessa pesquisa foram considerados todos os níveis de ensino.

Um fator dificultador percebido ao fazer esse levantamento foi a não existência de uma denominação única, específica para essas atividades. Cabe ressaltar que vários termos são usados para atividades experimentais com significado semelhante, como, por exemplo, trabalho prático, atividades práticas e experiências laboratoriais. Neste estudo, a expressão "atividade experimental" significa experiências realizadas nos laboratórios de Química e somente foram analisados os trabalhos cujas atividades de Química experimental foram realizadas nesse espaço. Portanto, não foram consideradas as atividades demonstrativas em salas de aula ou pesquisas de campo fora do laboratório escolar.

\section{Procedimento Metodológico}

O presente estudo caracteriza-se como uma pesquisa bibliográfica, uma vez que realizamos um levantamento de teses e dissertações disponíveis no portal da Capes. Para esse levantamento utilizamos como palavras-chave "ensino de Química experimental" e "atividades práticas". Encontramos inicialmente 40 trabalhos. Entretanto, após a leitura de seus resumos observamos que somente 23 tratavam de atividades experimentais investigativas com resolução

DOI: Em andamento. 
de problemas. Os outros tratavam de questões relativas ao ensino teórico de química como: mapas conceituais para a aprendizagem de Química; internet e software no Ensino de Química; avaliação de aprendizagem em Química; conversas de professores sobre o envolvimento dos estudantes com a Química; análises de artigos publicados na revista QNEs; oficinas pedagógicas para professores de ciências visando entre outras abordagens, preparação dos mesmos para o ensino experimental e atividades desenvolvidas em ambientes diversificados, mas não em laboratório de Química, dentre outros.

Para realizarmos o mapeamento desses 23 trabalhos, seguimos as orientações de Bardin (2007), e organizamos os dados fazendo, inicialmente, leituras para estabelecer as categorias de análise e o foco da pesquisa. Em seguida, realizamos o fichamento (pré-análise) para cada resumo contendo informações gerais e específicas na forma de itens: título, autores, linha de pesquisa, local e ano de publicação, instituição de origem, foco temático, objetivos, referencial teórico, processos metodológicos, resultados e contribuição para a área.

Após essa pré-análise, realizamos a leitura dos resumos e os categorizamos por focos temáticos de acordo com Bardin (2007). Encontramos dois focos: um no professor e o outro no aluno, com três subfocos cada, conforme pode ser observado na Tabela 1.

Tabela 1 - Distribuição dos trabalhos pesquisados no portal da Capes

\begin{tabular}{ll}
\hline Focos temáticos & Subfocos \\
\hline $\begin{array}{l}\text { 1.1-Características, crenças, concepções, saberes sobre ensino e aprendizagem de } \\
\text { Química experimental. } \\
\text { 1-Foco no Professor }\end{array}$ & $\begin{array}{l}\text { 1.2-Formação (domínio e desenvolvimento conceitual). Aspectos epistemológicos e } \\
\text { pedagógicos da prática desse ensino. Discursos e saberes }\end{array}$ \\
1.3-Formação continuada e desenvolvimento profissional. \\
2.1-Estratégia de ensino \\
2.2-Saberes \\
2.3-Aprendizagem
\end{tabular}

(Fonte: Elaborada pelas autoras)

\section{Resultados e Análise}

Como citado anteriormente, foram selecionados 23 produções acadêmicas que atendiam ao nosso objeto de estudo, sendo 19 dissertações e 4 teses como pode ser observado na Tabela 2. 
Tabela 2 - Número de produções acadêmicas selecionadas.

\begin{tabular}{lcc}
\hline Características dos trabalhos & № & $\%$ \\
\hline Teses (Doutorado) & 4 & 17,4 \\
Dissertações (Mestrado) & 16 & 69,6 \\
Dissertações (Mestrado profissional) & 3 & 13,0 \\
\end{tabular}

(Fonte: Elaborada pelas autoras)

Os dados apresentados nessa tabela mostram um número pequeno de trabalhos. Considerando o aumento do número de cursos de formação de professores e cursos de pós graduação nos últimos anos, citados por Queiroz et al (2003) e, constados por nós nos dias atuais, esperávamos encontrar um número maior de trabalhos. Entretanto, isto não ocorreu sinalizando que dificuldades relativas à implantação e funcionamento do laboratório e o preparo dos professores, são aspectos que continuam limitando a utilização das atividades experimentais mesmo que elas sejam consideradas importantes estratégias de ensino.

Após o fichamento dessas produções acadêmicas, observamos que houve um crescimento de pesquisas no período analisado, sendo $70 \%$ oriundos de universidades públicas. 0 fato de essas universidades contarem com condições que propiciam o desenvolvimento dessas pesquisas, como: professores pesquisadores em regime de dedicação exclusiva; boa infra-estrutura; apoio financeiro das próprias universidades e de órgãos de fomento à pesquisa e grupos de pesquisa consolidados, contribui para esta constatação. Foram duas pesquisas de doutorado, defendidas em 2008, uma na Universidade Federal de Minas Gerais (UFMG) e outro na Universidade Federal Fluminense (UFF) e as outras duas defendidas em 2011, sendo uma na UFMG e a outra na Universidade Cruzeiro do Sul (UNICSUL).

Foi possível identificar, ainda, que $39 \%$ dos trabalhos focam o professor e $61 \%$ focam o aluno. Acreditamos que o maior número de trabalhos com o foco no aluno seja um reflexo da tendência desse ensino. Segundo Mól (2011), existem indicadores da importância que a área de ensino de Química tem assumido no contexto social da nossa sociedade e por isso tem exigido um ensino mais comprometido com a formação de cidadãos, que tenham clareza de seus direitos e deveres com a sociedade e com o ambiente. São eles: o crescimento de cursos de pós-graduação, a produção de livros didáticos disponíveis, o crescente número de mestres e doutores e as importantes ações dos Encontros Nacionais de Ensino de Química (ENEQ) que têm intensificado a

DOI: Em andamento. 
interlocução de grupos de pesquisa, além de promover interação entre professores, pesquisadores para discutirem idéias e produções nessa área.

As informações apresentadas foram extraídas a partir de cada resumo, exceto de três trabalhos cujos resumos não informavam o processo de realização da pesquisa, nem os aportes teóricos que os sustentavam. Assim, nesses casos, a alternativa para fazer o fichamento completo foi buscar as informações no próprio trabalho e não apenas no resumo. Nesse sentido, percebemos que os resumos mais bem elaborados foram àqueles que apresentaram de forma concisa: objetivos claros; o problema e as questões que nortearam o estudo; os processos metodológicos utilizados; os resultados que respondiam aos objetivos e uma conclusão sintética, bem como, os principais referenciais teóricos e as possíveis contribuições deste estudo. Há de se considerar ainda que $65 \%$ desses trabalhos apresentam títulos que revelam o que está contido no seu respectivo resumo, demonstrando clareza e objetividade. Essa constatação foi percebida principalmente nos trabalhos mais recentes, demonstrando uma tendência.

A tabela 3 mostra o resultado da análise das informações contidas em cada resumo em relação à existência de objeto de estudo, foco, aportes teóricos, metodologia, resultados e contribuições para a área.

Tabela 3 - Análise das informações apresentadas nos resumos.

\begin{tabular}{lll}
\hline Detalhamento & No & \% \\
\hline Apresentam o objeto de estudo & 23 & 100,0 \\
Apontam a questão foco & 16 & 69,6 \\
Informam os aportes teóricos claramente & 11 & 47,8 \\
Sinalizam os aportes teóricos & 9 & 39,1 \\
Apresentam a metodologia utilizada & 23 & 100,0 \\
Detalham onde a pesquisa foi realizada & 18 & 78,3 \\
Detalham quem são os sujeitos da pesquisa & 19 & 82,6 \\
Informam como os dados foram coletados & 19 & 82,6 \\
Informam os resultados obtidos & 20 & 87,0 \\
Informam a contribuição que a pesquisa gerou para a área & 10 & 43,5 \\
\hline
\end{tabular}

(Fonte: Elaborada pelas autoras) 
Verificamos nessa tabela que $48 \%$ dos resumos informaram os aportes teóricos utilizados, $13 \%$ e $39 \%$ apenas sinalizavam, ou seja, não mencionavam os pesquisadores, mas apenas as principais idéias.

O gráfico 1 apresenta os focos e subfocos relacionados ao ensino de Química Experimental.

Gráfico 1 - Focos e subfocos temáticos

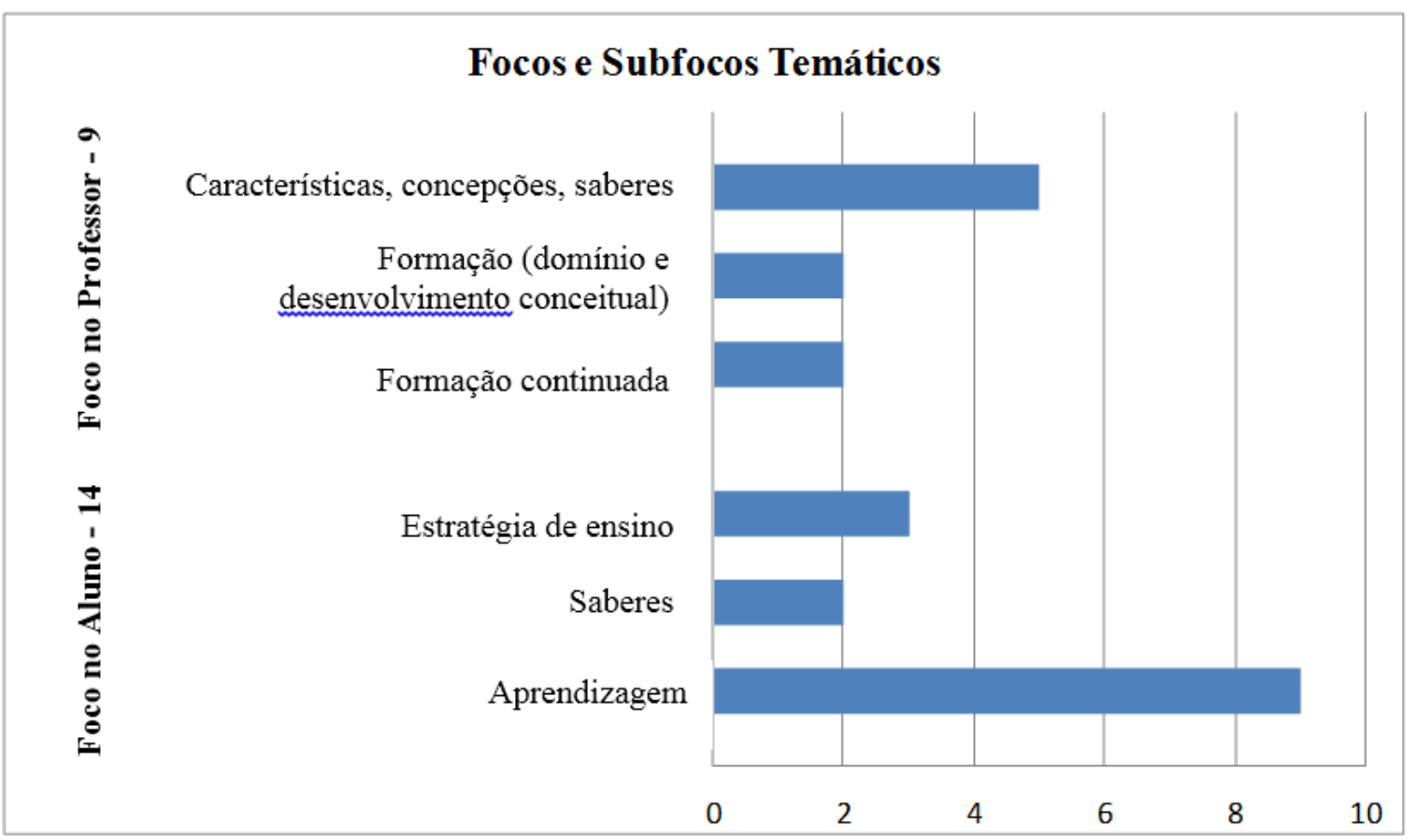

(Fonte: Elaborado pelas autoras)

A partir desse gráfico podemos observar nove trabalhos para o foco que trata o professor, suas características, concepções, saberes, desenvolvimento profissional, formação prática e formação continuada. Desses nove, selecionamos cinco num subfoco que trata especificamente da prática docente, crenças, concepções e saberes sobre ensino de Química experimental, representando $56 \%$ do total deste foco. Esse fato pode ser atribuído ao aumento de ações direcionadas aos futuros professores dos cursos de licenciatura em Química e também para aqueles em formação continuada, em cursos, encontros, congressos, além das publicações específicas destinadas a eles como a Revista Química Nova na Escola (ENEsc), como explica Mól (2011). Esses trabalhos abordam as concepções sobre o uso pedagógico da experimentação Química, a razão de usar ou não as atividades experimentais, as dificuldades encontradas para o desenvolvimento dessas práticas e a importância de categorizar a seleção de experimentos.

Para os outros subfocos relacionados ainda à formação dos professores, encontramos quatro trabalhos, dos quais dois abordam a formação do professor, seu domínio e

DOI: Em andamento. 
desenvolvimento conceitual, sendo um relativo ao desenvolvimento de material instrucional para Química Geral e outro sobre o funcionamento de um curso de licenciatura de uma instituição pública no Estado do Alagoas. Os outros dois foram incluídos no subfoco que trata da formação continuada de professores. Um investigou como os professores preparam os planos de aulas e o outro pesquisou o desenvolvimento de estratégias de ensino e a construção de software para aulas práticas virtuais e outros materiais instrucionais.

Para quatorze trabalhos com o foco no aluno e em seus processos de ensino aprendizagem, temos três trabalhos no subfoco das estratégias de ensino, dois relacionados aos saberes que o aluno adquire ao fazer aplicação da teoria na prática e nove relacionados aos processos cognitivos dos alunos. Dentro do subfoco das estratégias de ensino, os três trabalhos abordaram análise e caracterização de estratégias enunciativas de ensino de termoquímica, de sequência didática para interações intermoleculares e atividades práticas para identificar os elementos químicos. Já no subfoco dos saberes, temos uma dissertação que trata da avaliação do ensino experimental para conectar os conhecimentos químicos à análise de solos, e uma tese que trata do acompanhamento dos ensaios químicos de controle de qualidade, com abordagem de Ciência Tecnologia e Sociedade (CTS) e o desenvolvimento de valores e atitudes frente a essa abordagem.

Ainda para o foco no aluno, dos quatorze trabalhos, destacamos nove relacionados ao subfoco aprendizagem, representando $64 \%$ do total deste foco. Esse dado pode ser explicado pelo fato da experimentação em laboratório auxiliar os alunos a conseguirem níveis mais elevados de cognição e isto facilitarem a aprendizagem que, segundo Gonçalves e Marques (2006), contribuem também para a aprendizagem de atitudes. Esses trabalhos apresentam as seguintes abordagens: a didática mais utilizada nas aulas práticas; o pensamento dos estudantes e as contribuições significativas para o ensino de ácidos e bases em um dos trabalhos e sobre substâncias químicas em outro; a compreensão de como ocorre a construção da aprendizagem sobre leis ponderais; como o tempo é utilizado em aulas práticas de termoquímica e velocidade de reações; como promover a construção do conhecimento sobre situações-problema em um laboratório de Química; a argumentação e estrutura cognitiva utilizada pelos alunos na resolução de problemas de Química Analítica Qualitativa; o entendimento de como se dá a evolução de uma habilidade técnica com o tempo.

Desses nove trabalhos analisados para a aprendizagem dos alunos, temos duas teses, a de Silva (2008), que trata sobre as estratégias enunciativas de ensino de Termoquímica, e a de Alvim (2011), que estudou o desenvolvimento da habilidade técnica de titulação em um laboratório escolar. Ainda dentro da subcategoria de aprendizagem, foram abordados a didática mais utilizada, o pensamento dos alunos, a construção da aprendizagem sobre diversos conceitos químicos, a construção do conhecimento durante a resolução de problemas em um laboratório de química, bem como o uso da argumentação e da estrutura cognitiva nessa situação. 
Quanto aos trabalhos focados no aluno, destacamos quatro (Goi , 2004; Araújo, 2008, Júnior, 2009; Domingos, 2011) em que as atividades experimentais foram utilizadas como estratégia de ensino para resolução de problemas, permitindo a contextualização e o estímulo às discussões e aos questionamentos de investigação por parte dos alunos. De acordo com esses autores essa estratégia ajudou na construção de conceitos, de atitudes dos estudantes em relação ao conhecimento químico, bem como, aquisição de autonomia em relação aos problemas propostos.

A Tabela 4 apresenta os pesquisadores, os subfocos e os objetivos de cada trabalho que apresentou como categoria o foco no professor.

Tabela 4 -Subfocos, pesquisadores e objetivos de cada trabalho cujo foco é o professor.

\begin{tabular}{|c|c|c|}
\hline Subfocos & Pesquisadores & Objetivo principal \\
\hline \multirow{6}{*}{$\begin{array}{l}\text { 1.1. Características, } \\
\text { concepções e saberes } \\
\text { sobre ensino Química }\end{array}$} & Araujo (2007) & Estabelecer a importância das categorias de experimentos. \\
\hline & Salvadego (2007) & Compreender as razões de uso ou não de experimentos. \\
\hline & Moura (2008) & Investigar concepções sobre o uso pedagógico da \\
\hline & & experimentação como estratégia de ensino aliada a teoria \\
\hline & Walvy (2008) & Explicitar a construção do saber docente interdisciplinar \\
\hline & Clauzen (2010) & Conhecer as dificuldades dos professores - experimentos \\
\hline \multirow{3}{*}{$\begin{array}{l}\text { 1.2. Formação - } \\
\text { prática desse ensino. } \\
\text { Discursos e saberes }\end{array}$} & Cesar (2008) & Desenvolver material instrucional de experimentos \\
\hline & & Sistema Universidade Aberta do Brasil \\
\hline & Silva (2010) & Funcionamento de um curso Licenciatura em Alagoas \\
\hline \multirow{3}{*}{$\begin{array}{l}\text { 1.3. Formação } \\
\text { continuada e } \\
\text { desenvolvimento } \\
\text { profissional. }\end{array}$} & Silva (2011) & $\begin{array}{l}\text { Investigar o preparo dos planos de aulas priorizando o } \\
\text { desenvolvimento de habilidades cognitivas em atividades } \\
\text { experimentais investigativas. }\end{array}$ \\
\hline & Vieira (2011) & Propor desenvolvimento de estratégia de ensino e \\
\hline & & Software de aulas práticas virtuais. \\
\hline
\end{tabular}

(Fonte: Elaborado pelas autoras.)

R. B. E. C. T., vol 8, núm. 1, jan-abr.2015 ISSN - 1982-873X

DOI: Em andamento. 
A Tabela 5 apresenta os pesquisadores, os subfocos e os objetivos de cada trabalho que apresentou como categoria o foco no aluno.

Tabela 5 - Subfocos, pesquisadores e objetivos de cada trabalho cujo foco é o aluno.

\begin{tabular}{|c|c|c|}
\hline Subfocos & Pesquisadores & Objetivo principal \\
\hline \multirow{4}{*}{$\begin{array}{l}\text { 2.1. Estratégia de } \\
\text { ensino }\end{array}$} & Bossolani (2004) & Identificar elementos químicos em produtos comerciais. \\
\hline & Silva (2008) & Analisar e caracterizar estratégias enunciativas de dois \\
\hline & & professores, durante o ensino de Termoquímica. \\
\hline & Ferreira (2010) & Propor sequência didática: interações intermoleculares. \\
\hline \multirow[b]{2}{*}{ 2.2. Saberes } & Casagrande (2006) & Avaliar o ensino experimental para estudo sobre solos. \\
\hline & Santos (2011) & $\begin{array}{l}\text { Acompanhar os ensaios químicos e verificar se houve } \\
\text { desenvolvimento de valores e atitudes CTS. }\end{array}$ \\
\hline \multirow{14}{*}{ 2.3. Aprendizagem } & Goi (2004) & $\begin{array}{l}\text { Trazer contribuições para o ensino de ácidos e bases por } \\
\text { meio de resolução de problemas. }\end{array}$ \\
\hline & Costa (2004) & $\begin{array}{l}\text { Analisar os significados químicos construídos pelos } \\
\text { estudantes sobre as substâncias químicas. }\end{array}$ \\
\hline & Silva (2006) & Compreender a aprendizagem sobre Leis ponderais \\
\hline & Araujo (2008) & Identificar como o tempo é utilizado nas aulas práticas \\
\hline & & sobre Termoquímica e Velocidade de reações. \\
\hline & Junior (2009) & Investigar a construção do raciocínio, a argumentação na \\
\hline & & resolução de problemas de Química Analítica Qualitativa. \\
\hline & Lauxen (2010) & Investigar atividades de química e a construção de \\
\hline & & conhecimentos e a (re) significação conceitual. \\
\hline & Sato (2011) & Analisar a didática aplicada nas aulas práticas de Química \\
\hline & & e o desenvolvimento de um espírito investigativo. \\
\hline & Domingos (2011) & $\begin{array}{l}\text { Promover a experimentação a partir de assimilação, } \\
\text { acomodação e equilibração de Piaget. }\end{array}$ \\
\hline & Alvim (2011) & Entender a evolução de uma habilidade técnica de \\
\hline & & Titulação com o tempo e as ações dos estudantes. \\
\hline
\end{tabular}

(Fonte: Elaborado pelas autoras.) 
Ao analisar esses resumos, observando os objetivos de cada pesquisa, verificamos coerência teórico-metodológica para o desenvolvimento das atividades propostas. Nesse sentido, a compreensão do que cada pesquisa pretendia investigar foi facilitada quando seu objetivo foi relacionado com o foco e subfoco correspondente. Assim, esses objetivos deixam claro o que se pretende investigar e estão implícitos no título de cada trabalho, mostrando o cerne da questão investigada. Analisando ainda os objetivos e a descrição dos trabalhos por foco, observamos que existe um predomínio das atividades experimentais utilizadas como estratégia de ensino que visa explicitamente a construção do conhecimento químico para a resolução de problemas ( $56 \%$ dos trabalhos do subfoco aprendizagem do aluno). Os resultados descritos nos resumos indicaram que essa estratégia ajudou na construção de conceitos, de atitudes dos estudantes em relação ao conhecimento químico, bem como, aquisição de autonomia em relação aos problemas propostos.

Comparando o mapeamento das teses e dissertações apresentado neste artigo com os levantamentos dos pesquisadores citados na introdução, percebemos que o uso das atividades investigativas para o ensino de Química experimental também aparece nos resultados desses trabalhos, mesmo não sendo o foco dessas pesquisas que trataram o ensino de Química de maneira geral.

\section{Conclusões}

Os trabalhos investigados neste estudo mostraram que houve um predomínio de pesquisas sobre o ensino de Química experimental com o foco aluno, mais especificamente na sua aprendizagem. Dentro do foco no professor, destacamos os trabalhos de pesquisas sobre características, crenças, concepções e saberes sobre ensino e aprendizagem de Química experimental com destaque para a importância do papel do professor, que consiste em dialogar com os estudantes, respeitando-os à medida que os desafia a reorganizar o pensamento de forma mais crítica.

Entendemos que esses trabalhos são muito importantes para o ensino de química experimental, pois leva o professor a pensar a sua prática e propor, a partir desses resultados, outros desafios aos alunos, orientando-os nos trabalhos de investigação. Além disso, contribui também para a utilização de uma estratégia de ensino eficiente que ajuda o aluno a aprender.

\section{Referências}

ALVIM, T. R. Desenvolvimento da habilidade técnica de titulação em um laboratório escolar de Química. 2011. 118 f. Tese (Doutorado em Educação) - Universidade Federal de Minas Gerais, Belo Horizonte, 2011.

DOI: Em andamento. 
ARAUJO, A. O. O uso do tempo e as práticas epistêmicas em aulas práticas de Química. 2008. 298 f. Dissertação (Mestrado em Educação) - Universidade Federal de Minas Gerais, Belo Horizonte, 2008.

ARAUJO, N. R. S. Categorias para a seleção de experimentos de Química no ensino médio: um estudo comparativo das prioridades dos professores e licenciados em formação. 2007. 178 f. Dissertação (Mestrado em Ensino de Ciências e Educação Matemática) - Universidade Estadual de Londrina, Londrina, 2007.

BARDIN, L. Análise de conteúdo. Lisboa: Edições 70, 2007.

BOSSOLANI, K. Características da aprendizagem significativa em proposições expressas por escrito pelos alunos do ensino fundamental: um estudo de conceitos químicos propostos a partir de atividades experimentais. 2004. 214 f. Dissertação (Mestrado em Educação) - Universidade Federal de São Carlos, São Carlos, 2004.

CASAGRANDE, E. C. M. O papel da experimentação no estudo do solo através do ensino de química: relações entre ensino e aprendizagem numa perspectiva construtivista. 2006. $88 \mathrm{f}$. Dissertação (Mestrado em Educação Agrícola) - Universidade Federal Rural do Rio de Janeiro, Seropédica, 2006.

CESAR, J. Material Instrucional para Química geral experimental: uma contribuição à Universidade aberta do Brasil. 2008. 100 f. Dissertação (Mestrado em Química) - Universidade Estadual de Campinas, Campinas, 2008.

CLAUZEN, H. M. Compreender e Transformar o Ensino de Química: o laboratório como recurso auxiliar à prática docente. 2010. 167 f. Dissertação (Mestrado em Educação) - Universidade Católica de Santos, Santos, 2010.

COSTA, E. L. Análise das interações discursivas de uma seqüência introdutória de ensino: aprendizagem do conceito de substância. 2004. 125 f. Dissertação (Mestrado em Educação), Universidade de São Paulo, São Paulo, 2004.

DOMINGOS, D. C. A. Sequência didática investigativa em aulas experimentais no ensino médio de química para compreensão do termo extração e os fatores que ocorrem durante a destilação por arraste a vapor aplicando o padrão argumentativo de Toulmin. 2011. 116 f. Dissertação (Mestrado Profissional em Ensino de Ciências) - Universidade Federal do Mato Grosso do Sul, Campo Grande, 2011.

FERREIRA, A. S. Uma proposta teórico-experimental de sequência didática sobre interações intermoleculares no ensino de Química, utilizando o teste da adulteração da gasolina utilizando corantes de urucum. 2010. 173 f. Dissertação (Mestrado Profissional em Ensino de Ciências) Universidade Federal de Mato Grosso do Sul, Campo Grande, 2010. 
GIL PÉREZ, D. et al. Tiene sentido seguir distinguiendo entre aprendizaje de conceptos, resolución de problemas de lápiz y papel y realización de prácticas de laboratorio? Ensenãnza de las Ciencias, v. 17, n. 2, p. 311-320, 1999.

GOI, M. E. J. A Construção do conhecimento químico por estratégias de resolução de problemas. 2004. 151 f. Dissertação (Mestrado em Ensino de Ciências e Matemática) - Universidade Luterana do Brasil, Gravataí, 2004.

GOLDENBERG, M. A arte de pesquisar: como fazer pesquisa qualitativa em Ciências Sociais. $8^{\text {a }}$ edição Rio de Janeiros: Record, 2004.

GONÇALVES, F.P. e MARQUES, C. A. Contribuições pedagógicas e epistemológicas em textos de experimentação no ensino de Química. Investigações em Ensino de Ciências, v. 11, n. 2, p. 219$238,2006$.

JUNIOR, A. F. A formação do pensamento reversível no ensino de Química Analítica Qualitativa. 2009. 180 f. Dissertação (Mestrado em Educação) - Universidade de São Paulo, São Paulo, 2009.

LAUXEN, M. T. C. Atividades práticas e processos de construção de conhecimentos escolares em aulas de Química no ensino médio. 2010. 90 f. Dissertação (Mestrado em Educação nas Ciências), Universidade Regional do Noroeste do Estado do Rio Grande do Sul, ljuí, 2010.

MÓL, G. S. O Ensino da Química no ano internacional da Química. Revista de Educação, Cências e Matemática, Rio de Janeiro, v. 1 n. 1, p. 20-35, ago/dez. 2011

MOURA, G. N. Visões e virtudes pedagógicas do ensino experimental da Química: o que dizem professores de química que utilizam a experimentação em suas práticas pedagógicas. 2008. 62 f. Dissertação (Mestrado em Educação em Ciências e Matemática) - Universidade Federal do Pará, Guamá, 2008.

QUEIROZ, S.L.; NASCIMENTO, F.B.; REZENDE, F.S. Análise dos trabalhos apresentados nas reuniões anuais da Sociedade Brasileira de Química na seção de Ensino de Química de 1999 a 2003. In: Encontro Nacional de Pesquisa em Educação em Ciências, n. 4, 2003, Bauru.

SALVADEGO, W. N. C. A atividade experimental no ensino de Química: uma relação com o saber profissional do professor da escola média. 2007. 157 f. Dissertação (Mestrado em Ensino de zCiências e Educação Matemática) - Universidade Estadual de Londrina, Londrina, 2007.

SANTOS, M. S. Temas sociocientíficos em aulas práticas de química na educação profissional: uma abordagem CTS. 2011. 274 f. Tese (Doutorado em Ensino de Ciências) - Universidade Cruzeiro do Sul, São Paulo, 2011.

SANTOS, W. L. P.; SCHNETZLER, R. P. Função social: o que significa ensino de Química para formar o cidadão? Química Nova na Escola, n. 4, p. 28-34, nov. 1996.

DOI: Em andamento. 
SATO, M. S. A aula de laboratório no ensino superior de química. 2011. 115 f. Dissertação (Mestrado em Química) - Universidade de São Paulo, São Carlos, 2011.

SCHNETZLER, R. Pesquisa em ensino de química no Brasil: conquistas e perspectivas. Química Nova, v. 25, supl. 1, p. 14-24, 2002.

SILVA, A. C. T. As estratégias enunciativas de professores de química. 2008. 315 f. Tese (Doutorado em Educação) - Universidade Federal de Minas Gerais, Belo Horizonte, 2008.

SILVA, C. S. Estudo da unidade de aprendizagem no ensino de Química para aprendizagem significativa das leis ponderais. 2006. 133 f. Dissertação (Mestrado em Educação em Ciências e Matemática), Pontifícia Universidade Católica do Rio Grande do Sul, Porto Alegre, 2006.

SILVA, D. P. Questões propostas no planejamento de atividades experimentais de natureza investigativa no ensino de química: reflexões de um grupo de professores. 2011. $212 \mathrm{f}$. Dissertação (Mestrado em Ensino de Ciências), Universidade de São Paulo, São Paulo, 2011.

SILVA, F. A. S. Contribuições do laboratório de ensino do Instituto de Química de Biotecnologia na formação do licenciado em Química da UFAL. 2010. 110 f. Dissertação (Mestrado em Educação) - Universidade Federal de Alagoas, Maceió, 2010.

SUART, R. C.; MARCONDES, M. E. R. A manifestação de habilidades cognitivas em atividades experimentais investigativas no ensino médio de química. Ciências e Cognição, v. 14, p. 50-74, 2009.

SUART, R. C.; MARCONDES, M. E. R.; LAMAS, M. F. P. A estratégia "Laboratório Aberto" para a construção do conceito de temperatura de ebulição e a manifestação de habilidades cognitivas. Química Nova na Escola, v. 32, n. 3, p. 200-207, 2010.

VIEIRA, E. Aulas práticas virtuais como instrumento de aprendizagem no Ensino de Química. 2011. 87 f. Dissertação (Mestrado Profissional em Ensino em Ciências da Saúde e do Meio Ambiente) - Centro Universitário de Volta Redonda, Volta Redonda, 2011.

WALVY, O. W. C. Construindo saber docente interdisciplinar: a termogravimetria em um laboratório didático. 2008. 231 f. Tese (Doutorado em Ensino de Educação) - Universidade Federal Fluminense, Niterói, 2008.

Profa Heloisa Helena J. Ferreira

Formação acadêmica - Mestre em Educação Tecnológica pelo CEFET-MG e doutoranda em Ensino de Ciências e Matemática pela UNICSUL

Instituição em que trabalha - Centro Federal de Educação Tecnológica de Minas Gerais- CEFETMG. 
Função- docente do Departamento de Química

Endereço - Av. Amazonas 5253. Belo Horizonte- MG. E-mail: heloisa@deii.cefetmg.br

Profa Dra Carmem Lúcia C. Amaral

Formação acadêmica: Doutora em Ciência - Química pela USP

Instituição em que trabalha: Universidade Cruzeiro do Sul -UNICSUL

Endereço: Rua Galvão Bueno 868. Liberdade São Paulo-SP

E-mail: carmem.amaral@cruzeirodosul.edu.br

DOI: Em andamento. 